University of Nebraska - Lincoln

DigitalCommons@University of Nebraska - Lincoln

\title{
Compositional and Mechanical Properties of Peanuts Roasted to Equivalent Colors using Different Time/Temperature Combinations
}

\author{
Kristin A. McDaniel \\ North Carolina State University at Raleigh \\ Brittany L. White \\ USDA ARS, brittany.white@ars.usda.gov \\ Lisa L. Dean \\ North Carolina State University at Raleigh, Lisa.Dean@ars.usda.gov \\ Timothy H. Sanders \\ USDA, ARS, tim.sanders@ars.usda.gov \\ Jack P. Davis \\ North Carolina State University at Raleigh, jack.davis@ars.usda.gov
}

Follow this and additional works at: https://digitalcommons.unl.edu/usdaarsfacpub

McDaniel, Kristin A.; White, Brittany L.; Dean, Lisa L.; Sanders, Timothy H.; and Davis, Jack P., "Compositional and Mechanical Properties of Peanuts Roasted to Equivalent Colors using Different Time/ Temperature Combinations" (2012). Publications from USDA-ARS / UNL Faculty. 1114.

https://digitalcommons.unl.edu/usdaarsfacpub/1114

This Article is brought to you for free and open access by the U.S. Department of Agriculture: Agricultural Research Service, Lincoln, Nebraska at DigitalCommons@University of Nebraska - Lincoln. It has been accepted for inclusion in Publications from USDA-ARS / UNL Faculty by an authorized administrator of DigitalCommons@University of Nebraska - Lincoln. 


\title{
Compositional and Mechanical Properties of Peanuts Roasted to Equivalent Colors using Different Time/Temperature Combinations
}

\author{
Kristin A. McDaniel, Brittany L. White, Lisa L. Dean, Timothy H. Sanders, and Jack P. Davis
}

\begin{abstract}
Peanuts in North America and Europe are primarily consumed after dry roasting. Standard industry practice is to roast peanuts to a specific surface color (Hunter $L$-value) for a given application; however, equivalent surface colors can be attained using different roast temperature/time combinations, which could affect product quality. To investigate this potential, runner peanuts from a single lot were systematically roasted using 5 roast temperatures $(147,157,167,177$, and $187^{\circ} \mathrm{C}$ ) and to Hunter $L$-values of $53 \pm 1,48.5 \pm 1$, and $43 \pm 1$, corresponding to light, medium, and dark roasts, respectively. Moisture contents (MC) ranged from $0.41 \%$ to $1.70 \%$ after roasting. At equivalent roast temperatures, $\mathrm{MC}$ decreased as peanuts became darker; however, for a given color, $\mathrm{MC}$ decreased with decreasing roast temperature due to longer roast times required for specified color formation. Initial total tocopherol contents of expressed oils ranged from 164 to $559 \mu \mathrm{g} / \mathrm{g}$ oil. Peanuts roasted at lower temperatures and darker colors had higher tocopherol contents. Glucose content was roast color and temperature dependent, while fructose was only temperature dependent. Soluble protein was lower at darker roast colors, and when averaged across temperatures, was highest when samples were roasted at $187^{\circ} \mathrm{C}$. Lysine content decreased with increasing roast color but was not dependent on temperature. MC strongly correlated with several components including tocopherols $\left(R^{2}=0.67\right)$, soluble protein $\left(R^{2}=0.80\right)$, and peak force upon compression $\left(R^{2}=0.64\right)$. The variation in characteristics related to roast conditions is sufficient to suggest influences on final product shelf life and consumer acceptability.
\end{abstract}

Keywords: Maillard browning, peanuts, roasting, sugar, tocopherol

Practical Application: Peanuts are typically dry roasted to a specified surface color for a given food application; however, it is possible to obtain equivalent colors using different temperatures. This simple observation led to the overall goal of this research which was to determine if peanuts roasted to equivalent surface colors using different temperatures are equivalent from a quality perspective. Several compositional and textural measurements important to product quality differed based on the temperature used to achieve a given roast color. Overall, this study suggests there is good potential to optimize peanut quality by simply adjusting the time/temperature profiles during roasting.

\section{Introduction}

The majority of peanuts in North America and Europe are consumed dry roasted, making the sensory and nutritional properties of these materials of valuable interest to the peanut industry. Proper roasting is critical to flavor and texture development as well as nutritional content of the final product. Standard industry practice is to roast peanuts to a specific color, as commonly quantified by the L-value of a Hunter colorimeter or similar measurement, as final seed color is a good indicator of product quality including flavor (Pattee and others 1991). Color development in peanuts results from Maillard browning reactions and to a lesser

MS 20121101 Submitted 8/10/2012, Accepted 9/25/2012 Authors McDaniel, Dean, Sanders, and Davis are with Dept. of Food, Bioprocessing and Nutrition Sciences, North Carolina State Univ., Schaub Hall, Raleigh, N.C. 27695, U.S.A. Authors White, Dean Sanders, and Davis are with Market Quality and Handling Research Unit, USDA ARS, 236 Schaub Hall, North Carolina State Univ., Raleigh, N.C. 27695,U.S.A. Direct inquiries to author Davis (E-mail: jack.davis@ars.usda.gov).

extent caramelization (Pattee and others 1991). As color develops during roasting, Maillard reactions produce various volatiles, which are important contributors, either directly or indirectly, to roasted peanut flavor (Chetschik and others 2010; Schirack and others 2006). Roasting also reduces moisture content (MC) and modifies the internal microstructure of peanuts to create the characteristic crunchy and crispy texture of roasted peanuts (Lee and Resurreccion 2006).

Raw peanuts have inherent antioxidant capacity. During roasting some antioxidants are lost due to heat instability, while others are formed via chemical reactions such as Maillard browning (van Boekel and others 2010). Maillard reaction products have high antioxidant capacities in model systems and roasted foods, including coffee, oilseeds, baked goods, and so on (Manzocco and others 2000; Yilmaz and Toledo 2005). Roasting also releases phenolic compounds such as p-coumaric acid and hydroxybenzoic acid from the cellular matrix, which can serve as antioxidants (Talcott and others 2005). Tocopherols (Vitamin E) are an important class of lipid soluble antioxidants in peanuts. During storage of peanuts under atmospheric conditions, degradation of tocopherols 
occurs more rapidly in moderately roasted peanuts as compared to raw peanuts (Chun and others 2005). Recent research indicates that under accelerated storage conditions $\left(85^{\circ} \mathrm{C}\right.$ in an open container), tocopherols in oil expressed from darker roasted peanuts was higher than that from moderately roasted, or even raw, peanuts (Davis and others 2010). Increased antioxidants resulting from the roasting process are thought to protect tocopherols in the darker roasted peanuts (Davis and others 2010).

While the industry typically roasts to a specific color for a given application, peanuts can be roasted to equivalent surface colors using different time/temperature combinations. This simple observation led to the overall goal of this research, which was to determine if peanuts roasted to equivalent surface colors using different temperatures are equivalent from a quality perspective. The kinetics of browning reactions contribute to, and are expected to correlate with, other key reactions in peanuts, and other roasted foods, associated with flavor, texture, antioxidant capacity, and so on (van Boekel and others 2010). Accordingly, we evaluated various compositional and texture quality characteristics of peanuts that were systematically dry roasted, using 5 different temperatures, to equivalent surface colors typically associated with "light," "medium," and "dark." Correlations among compositional and mechanical properties, as related to color development and roasting conditions were determined. This research results in a more comprehensive understanding of key reactions contributing to roasted peanut composition and texture, and may allow these properties to be optimized during industrial roasting. Flavor analysis of these samples is presented in a subsequent manuscript.

\section{Materials and Methods}

\section{Materials}

A representative sample of medium-grade size Georgia Green runner peanuts (Arachis hypogaea L.) were obtained from a single harvested lot. The peanuts had been harvested, cured, and shelled according to standard industry practices prior to delivery to the USDA ARS Market Quality and Handling Re-
Table 1-Average roasting times for all roast color and temperature combinations.

\begin{tabular}{lccccr}
\hline \multirow{2}{*}{$\begin{array}{l}\text { Roast color } \\
(\boldsymbol{L} \text {-Value })\end{array}$} & \multicolumn{5}{c}{ Time (min) } \\
\cline { 2 - 6 } & $\mathbf{1 4 7}{ }^{\circ} \mathbf{C}$ & $\mathbf{1 5 7}^{\circ} \mathbf{C}$ & $\mathbf{1 6 7}{ }^{\circ} \mathbf{C}$ & $\mathbf{1 7 7}^{\circ} \mathbf{C}$ & $\mathbf{1 8 7}{ }^{\circ} \mathbf{C}$ \\
\hline Light $(53 \pm 1)$ & 26.5 & 16.6 & 13.5 & 10.0 & 8.6 \\
Medium $(48.5 \pm 1)$ & 46.4 & 25.6 & 17.0 & 12.2 & 10.6 \\
Dark $(43 \pm 1)$ & 70.8 & 36.6 & 21.2 & 15.4 & 12.3 \\
\hline
\end{tabular}

search Unit where they were stored under refrigeration until needed.

\section{Peanut roasting}

Raw, shelled peanuts were removed from cold storage, tempered, and subsequently roasted in a lab scale oven (Despatch, Minneapolis, Minn., U.S.A.). Following roasting, samples were placed onto a forced air blower, manually blanched (seed coat or "skin" removed) with gloved hands and surface color was determined using a Hunter Colorimeter LAB DP-900 Colorimeter (Hunter Associates Lab., Reston, Va., U.S.A.). For each color measurement, a single layer of roasted peanut seed was spread in the bottom of a Petri dish and color was determined 3 times with rotation of the dish after each measurement. For the purposes of this study, light, medium, and dark roast surface colors were defined as blanched seed having $L$-values of $53 \pm 1,48.5 \pm 1$, and $43 \pm$ 1 , respectively. These surface colors were obtained using 5 different roast temperatures: $147,157,167,177$, and $187^{\circ} \mathrm{C}$. Roasting times were dependent on the defined roast color and temperature, and these times were determined using linear regression of preliminary roast curves (Figure 1). These resulting times are shown in Table 1.

\section{Moisture content (MC)}

Whole peanut seed from each time/temperature roast combination were placed in triplicate into aluminum pans, weighed, and transferred into an oven at $130^{\circ} \mathrm{C}$ for $6 \mathrm{~h}$. Peanuts were then cooled to ambient temperature, weighed, and MC was determined gravimetrically.

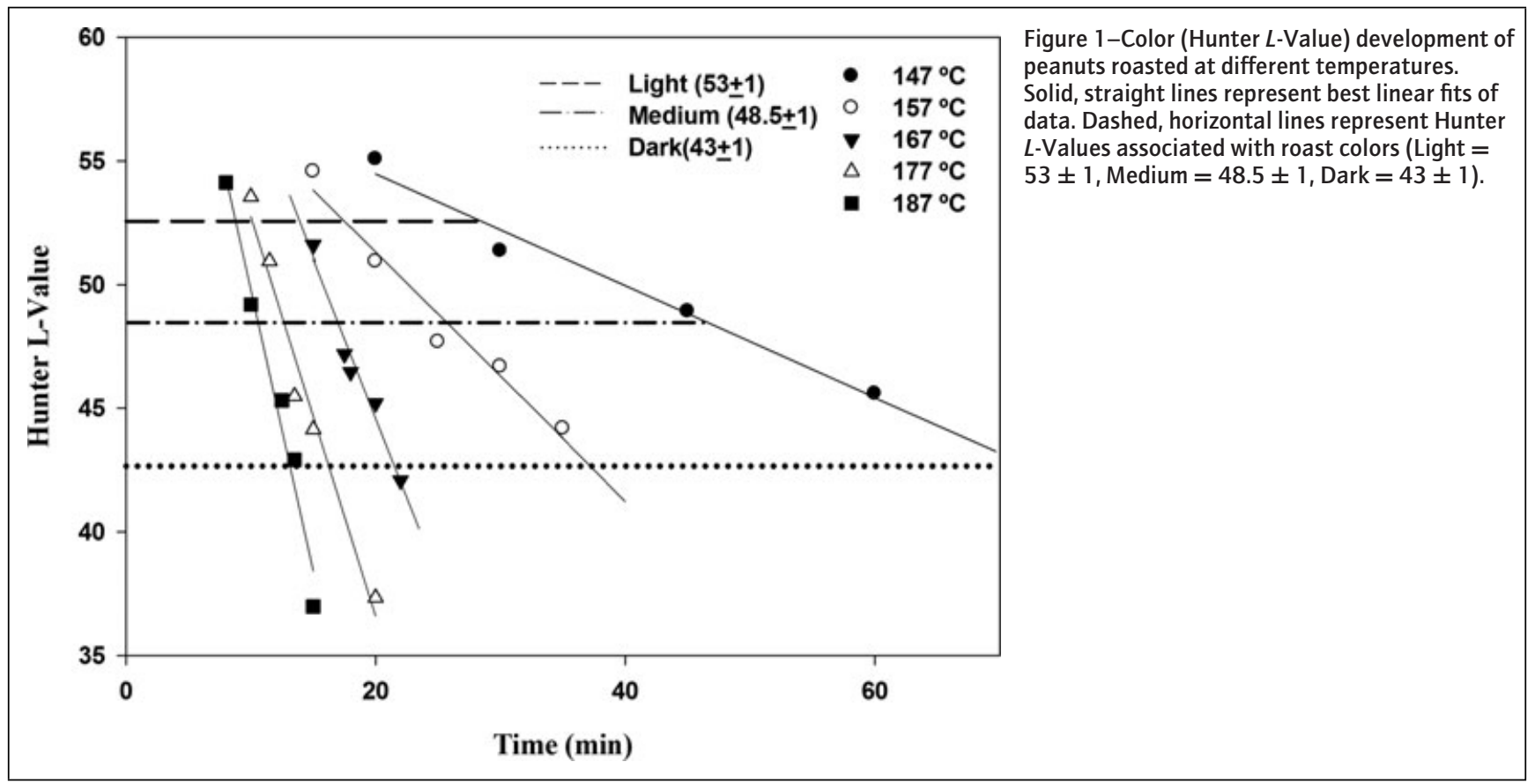




\section{HPLC analysis of sugars}

Samples were ground, wrapped in 2 layers of cheese cloth, and mechanically pressed to partially remove oil using a Carver press. Remaining peanut solids were defatted with hexane using a Soxhlet apparatus. Sugars were extracted by sonication with $60: 25: 15$ methanol : chloroform : deionized water (DI) for $20 \mathrm{~min}$, and analyzed according to a previously published method (Pattee and others 2000) and values are expressed as microgram per gram dry seed.

\section{Protein solubility}

Defatted, raw, and roasted ground peanuts $(1 \mathrm{~g})$ were suspended in $25 \mathrm{~mL}$ of $65 \mathrm{mM}$ tris- $\mathrm{HCl}$ buffer $(\mathrm{pH} 8.3)$ containing $1 \mathrm{mM}$ EDTA, $1 \mathrm{mM}$ phenylmethylsulfonyl fluoride, and $200 \mathrm{mM} \mathrm{NaCl}$ and allowed to shake at room temperature for $1 \mathrm{~h}$ to extract soluble protein. After centrifugation, the supernatant, which contained soluble peanut proteins, was collected. The remaining pellet was washed 2 more times with buffer and centrifuged, and all supernatants were pooled and stored at $-20{ }^{\circ} \mathrm{C}$ until further analysis. Soluble protein was quantified by the BCA assay using BSA as a standard. Values are expressed as milligram per gram of dry, defatted seed.

\section{Amino acids}

For amino acid analysis, samples $(0.05 \mathrm{~g})$ were digested with $4 \mathrm{~mL} 6 \mathrm{~N} \mathrm{HCl}$ containing $1 \%$ phenol using a CEM Discover microwave digestion system (CEM, Matthews, N.C., U.S.A.) at $165^{\circ} \mathrm{C}$ for $10 \mathrm{~min}$ and cooled with nitrogen. Following digestion, sample volumes were adjusted to $25 \mathrm{~mL}$ with $0.02 \mathrm{~N} \mathrm{HCl}$. Amino acids were analyzed using a Hitachi L-8900 Amino Acid Analyzer (Hitachi High Technologies Corporation, Tokyo, Japan) according to the operation manual. In this method, free amino acids from hydrolyzed protein are separated by ion exchange and derivatized with ninhydrin for detection at 570 or $440 \mathrm{~nm}$. A Natl. Inst. of Standards and Technology peanut butter standard was used as a reference. Data analysis was performed with EZChrom Elite software. Values are expressed as microgram per gram of dry seed.

\section{Oil stability-tocopherol and peroxide value analyses}

To obtain expressed oils, roasted samples were ground, wrapped in 2 layers of cheesecloth and mechanically pressed using a Carver press. Oils $(15 \mathrm{~mL})$ were stored in open Petri dishes under accelerated oxidative conditions of $85 \pm 3{ }^{\circ} \mathrm{C}$ and samples were collected after 0,1 , and $3 \mathrm{~d}$ for tocopherol analysis (Davis and others 2010) and after $7 \mathrm{~d}$ for peroxide value (PV). Tocopherols were analyzed by high-performance liquid chromatography (HPLC) as described by Davis and others (2010) and values expressed as microgram per gram oil. PV's were determined using the A.O.C.S Official Method Cd 8-53.

\section{Antioxidant capacity}

A Dionex (Sunnyvale, Calif., U.S.A.) Accelerated Solvent Extractor 200 was used to extract antioxidant compounds from raw and roasted peanuts and corresponding skins accordingly to previously published methods (Davis and others 2010; Wu and others 2004). Hydrophilic ORAC (H-ORAC) was measured according to a previously published procedure (Prior and others 2003) with modifications as described by (Davis and others 2010).

\section{Mechanical compression}

An Instron universal materials testing machine (model 5565; Instron, Norwood, Mass., U.S.A.) mounted with a 10 plate Kramer shear cell (KSC) and $5 \mathrm{kN}$ load cell was used to analyze multiseed mechanical properties during compression. The Instron was lowered at a crosshead speed of $100 \mathrm{~mm} / \mathrm{min}$ onto $15 \mathrm{~g}$ of whole peanut kernels from each sample evenly distributed with no overlapping in the KSC (internal dimensions: $70 \times 80 \times 55 \mathrm{~mm}$ ). Peak force was recorded and samples were analyzed in triplicate.

\section{Statistical analysis}

A complete randomized split plot block design was used. A block was defined as one week containing all 15 roast time/temperature combinations. Plots were represented by a day, which contained all roast colors for a given temperature. Within plots roast colors were randomly assigned to obtain a balanced distribution for each temperature. Analysis of variance (ANOVA) was performed using JMP ${ }^{\circledR}$ version 9.0 (SAS Inst. Inc., Cary, N.C., U.S.A.). Means were separated using a Student's $t$-test when a significant $F$-value was obtained.

\section{Results and Discussion}

\section{Moisture content (MC)}

$\mathrm{MC}$ of all 15 time/temperature treatments and the raw-blanched peanut seed are presented in Figure 2. All roasted samples have lower moisture than the raw-blanched sample. At a given roast temperature, $\mathrm{MC}$ decreased with increasing roast color. Additionally, at a given roast color, $\mathrm{MC}$ increased with increasing temperatures indicating that the longer roast times necessary to reach a given roast color facilitated moisture loss. MC is a critical factor affecting the flavor, texture, and shelf life of most foods, as MC generally influences the rate of numerous reactions important to food quality. As peanuts are roasted, moisture is released, and the amount released depends on both the roast temperature and time. As discussed below, MC of the roasted samples seemed to critically affect and/or correlate with numerous other chemical and physical measurements known to be important to final product quality.

\section{Sugars}

Sugar content is critical to the development of peanut color and flavor during processing, as these compounds, along with amino acids, are necessary for Maillard reactions (Baker and others 2003; Sanders and others 1989). Total of 6 sugars were identified in raw and roasted peanuts. Sucrose comprised approximately $88 \%$ of the total sugars and stachyose approximately $9 \%$. Raffinose, glucose, fructose, and myo-inositol were present in smaller quantities. Significant changes in glucose, fructose, stachyose, and raffinose contents were observed in response to roasting protocol. Total sugar content of raw and roasted peanuts (averaged across all conditions) was 4.1 and $3.7 \mathrm{~g} / 100 \mathrm{~g}$ DW, respectively.

Glucose content was more dependent upon roast color $(P<0.0001)$ than roast temperature $(P=0.0421)$. A significant decrease in glucose was observed between raw and light roasted peanuts; however, glucose content increased significantly with darker roast color (Table 2). Additionally, glucose content was negatively correlated with surface $L$-values $\left(R^{2}=0.79\right)$ and $\mathrm{MC}\left(R^{2}=0.63\right)$ as glucose is a primary substrate for the Maillard reaction. Fructose content was dependent upon roast temperature $(P<0.0001)$ but not roast color $(P=0.1204)$. Averaged across all roast colors, fructose content generally increased with increasing roast temperature (Table 3). These observations in glucose and fructose contents are likely explained by several competing reactions involving sugars during roasting. Beyond the baseline level of glucose and fructose naturally present in peanuts, factors 
influencing their levels during roasting include utilization during Maillard browning and/or caramelization, both of which decrease detectable levels. Additionally, glucose and fructose can be released by the inversion of sucrose, which increases detectable levels (Reyes and others 1982). It should be noted that sucrose concentrations exhibited a decreasing trend with increasing roast color, but this was not statistically significant $(P=0.0604)$; however, since sucrose is present at much higher concentrations than the monosaccharides, minor changes in sucrose content could strongly influence detectable fructose and glucose levels. Additional glucose could also be released from the breakdown of raffinose and stachyose, both of which decreased significantly with darkening roast color (Table 2). Increased roasting temperatures for equivalent roast times, or increasing roast times at equivalent temperatures are hypothesized to reduce levels of glucose and fructose, as these conditions likely favor Maillard browning and/or caramelization; however, higher roast temperatures and longer roast times also favor sucrose inversion and breakdown of oligosaccharides leading to increased levels of free glucose and fructose. As such, detected levels of glucose and fructose likely represent a balance of competing reactions, and further research is needed to better understand these relationships.

\section{Protein solubility and amino acids}

During roasting, peanut proteins undergo structural and conformational changes that can ultimately result in decreased solubility (Kopper and others 2005). As seen in Figure 3A, soluble protein correlated well with $\mathrm{MC}\left(R^{2}=0.80\right)$, indicating that $\mathrm{MC}$ either directly influences protein solubility or it acts as an indicator since samples with lower MCs received harsher roasting conditions (that is, higher temperatures and/or longer times). The amount of soluble protein was related to both roast color $(P<0.0001)$ and roast temperature $(P=0.0004)$. Raw samples had approximately $396 \mathrm{mg} / \mathrm{g}$ soluble protein, which is much higher than any roasted sample, and as roasting color darkened, soluble protein decreased (Figure 3A). This likely reflects structural modifications to peanut proteins and their participation in the Maillard reaction. Additionally, samples roasted at $187^{\circ} \mathrm{C}$ had more soluble protein than those roasted at any other temperature,
Table 2-Sugar and lysine contents $(\mu \mathrm{g} / \mathrm{g}$ dry seed) of raw peanuts and peanuts roasted to different colors averaged across all roast temperatures.

\begin{tabular}{llclc}
\hline $\begin{array}{l}\text { Roast } \\
\text { Color }\end{array}$ & \multicolumn{1}{c}{ Glucose } & Raffinose & \multicolumn{1}{c}{ Stachyose } & Lysine \\
\hline Raw & $55.5 \pm 18.3 \mathrm{~b}^{\mathrm{a}, \mathrm{b}}$ & $839.5 \pm 25.3 \mathrm{a}$ & $3965.8 \pm 83.3 \mathrm{a}$ & $0.70 \pm 0.01 \mathrm{a}$ \\
Light & $35.9 \pm 9.2 \mathrm{c}$ & $774.5 \pm 49.2 \mathrm{a}$ & $3503.5 \pm 407.7 \mathrm{~b}$ & $0.65 \pm 0.02 \mathrm{~b}$ \\
Medium & $46.8 \pm 6.5 \mathrm{~b}$ & $728.1 \pm 48.9 \mathrm{~b}$ & $3339.5 \pm 229.2 \mathrm{bc}$ & $0.60 \pm 0.01 \mathrm{c}$ \\
Dark & $63.3 \pm 7.0 \mathrm{a}$ & $701.1 \pm 65.3 \mathrm{~b}$ & $3181.4 \pm 302.9 \mathrm{c}$ & $0.54 \pm 0.02 \mathrm{~d}$ \\
\hline
\end{tabular}

${ }^{a}$ Values represent means \pm standard deviation $(n=3)$.

${ }^{b}$ Values within each column followed by different letters are significantly different $(P<0.05)$.

Table 3-Fructose content of raw peanuts and peanuts roasted at different temperatures averaged across all roast colors

\begin{tabular}{lc} 
Roast temperature $\left({ }^{\circ} \mathbf{C}\right)$ & Fructose $(\mu \mathbf{g} / \mathbf{g}$ dry seed $)$ \\
\hline Raw & $53.3 \pm 13.3 \mathrm{bc}^{\mathrm{a}, \mathrm{b}}$ \\
147 & $36.6 \pm 3.6 \mathrm{~d}$ \\
157 & $50.3 \pm 6.8 \mathrm{~b}$ \\
167 & $44.0 \pm 2.9 \mathrm{c}$ \\
177 & $54.5 \pm 2.8 \mathrm{ab}$ \\
187 & $57.4 \pm 7.0 \mathrm{a}$ \\
\hline
\end{tabular}

${ }^{a}$ Values represent means \pm standard deviation $(n=3)$.

${ }^{b}$ Values within each column followed by different letters are significantly different $(P<0.05)$.

indicating that lower temperature/longer roasting to equivalent colors decreased protein solubility. Increased roast times at a given temperature reduce protein solubility, which is attributed to crosslinking of glycoproteins as part of the Maillard reaction, resulting in proteins that are more resistant to in vitro model gastric and intestinal digestion (Kopper and others 2005). It has also been demonstrated that roasting increases the in vitro immunoglobulin $\mathrm{E}$ (IgE, a key mediator in food allergies) binding capacity of peanut proteins (Maleki and others 2000). Our data suggest that roasting time/temperature has implications for both the digestibility and $\mathrm{IgE}$ response of peanuts by altering protein solubility, with longer roasting times potentially decreasing digestibility. Therefore, in this respect, high temperature/short time roasting might be more favorable, but further investigations are warranted to understand the practical implications of these protein modifications.

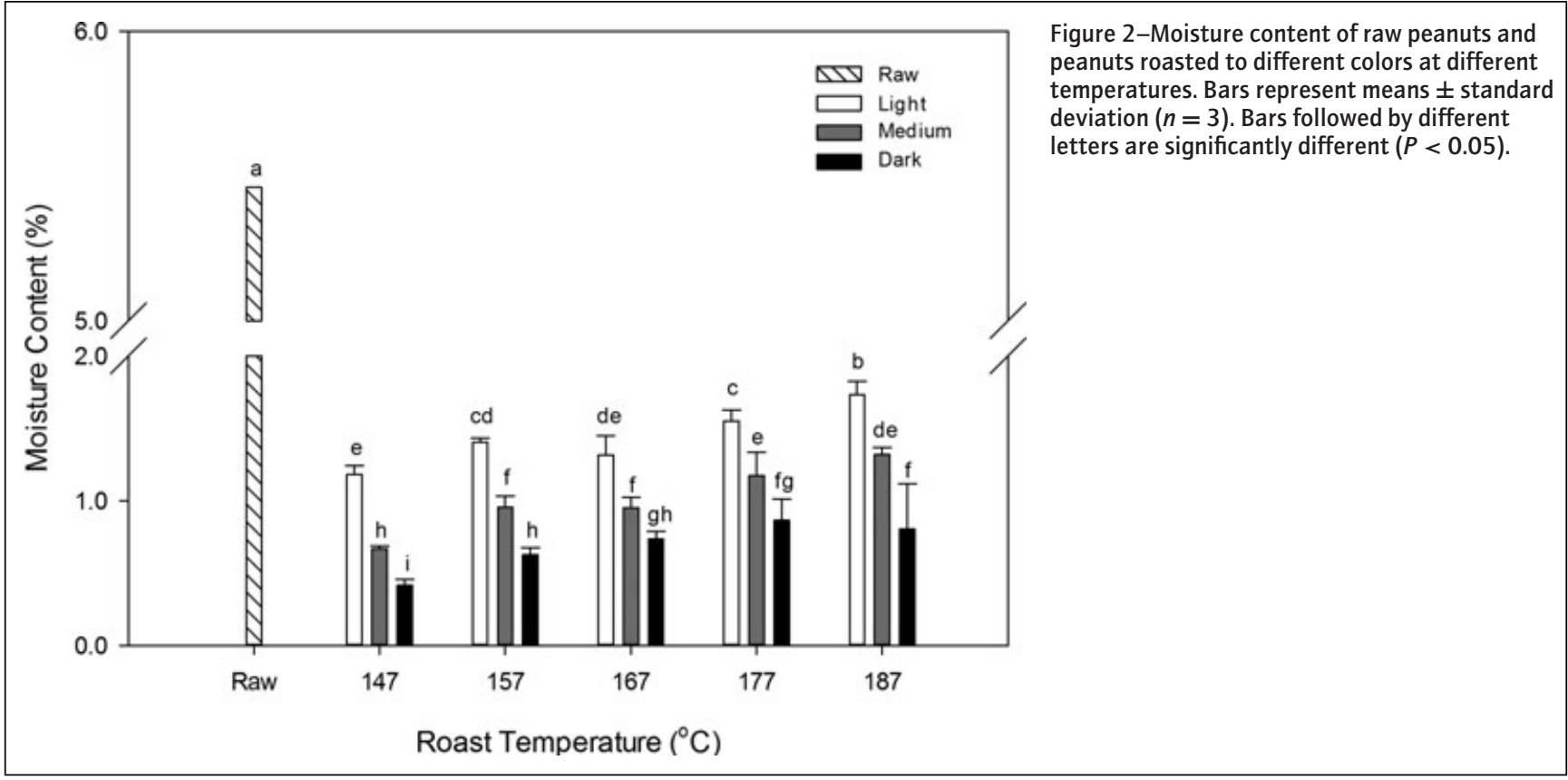


Sugars and amino acids of peanuts are involved in Maillard reactions during roasting, and lysine is a particularly reactive amino acid due to its free $\varepsilon$-amino group. Lysine content decreased from raw to light roasted samples and continued to decrease significantly $(P<0.0001)$ with darkening roast color, but was not affected by the temperature used in roasting $(P=0.1370)$ (Table 2$)$. Decreases in lysine content were $7 \%, 14 \%$, and $23 \%$ for light, medium, and dark roasted peanuts, respectively, compared to raw peanuts. Similar losses $(12.7 \%)$ in lysine content due to light roasting in defatted peanut meal were observed, although exact time/temperature roasting conditions were not indicated (Saalia and Phillips 2011).
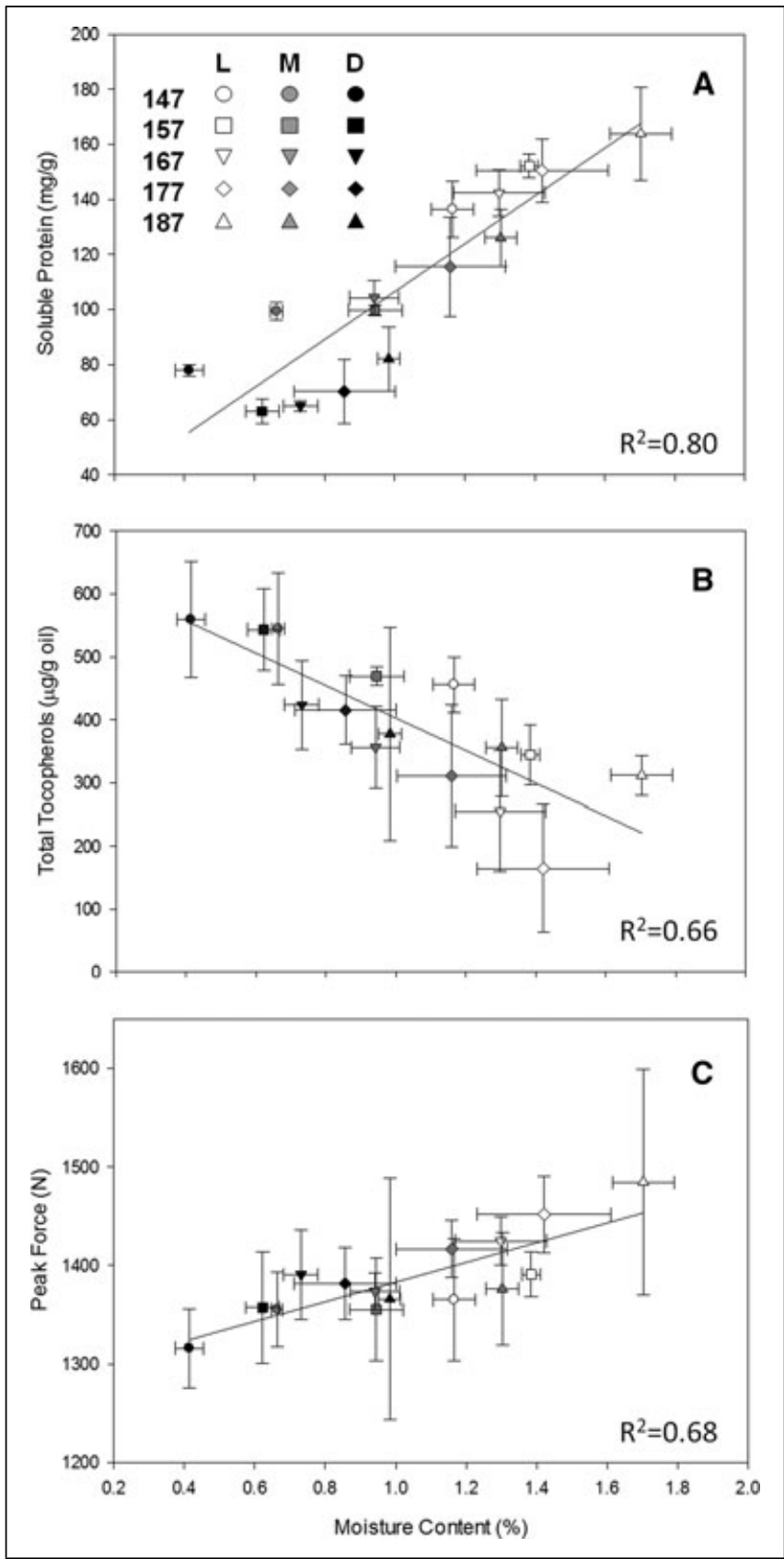

Figure 3-Linear correlations between moisture content and soluble protein (A), total tocopherols (B), and peak force (C) for peanuts roasted using various time/temperature combinations. Points are means \pm standard deviations $(n=3)$.
Oil stability-tocopherol and peroxide value analyses

Total of 4 tocopherols $(\alpha, \beta, \gamma$, and $\delta$ ) were identified in peanut oil consistent with previous research (Chun and others 2005). Total tocopherols were dependent upon roast color $(P<0.0001)$, temperature $(P<0.0001)$, and storage time $(P<0.0001)$, but the interactions were not significant (Figure 4$)$. Tocopherol content of the raw peanuts was approximately $423 \mu \mathrm{g} / \mathrm{g}$ oil, with $\alpha$ - and $\gamma$-tocopherol being most abundant. Since tocopherols are susceptible to degradation by heat, it was expected that oil from darker roasted peanuts would have lower tocopherol concentrations. However, as roast color darkened, tocopherol content of the oil increased (Figure 4A). Production of Maillard browning products, which have inherent antioxidant activity and hence the potential to protect the tocopherols from degradation, may in part explain this phenomenon. Expressed oils from the dark roasted seed were darker in color than oil from light or medium roasted seed, meaning some Maillard browning compounds were oil soluble. Oil from cashew nuts roasted to darker colors at high temperature/short time $\left(130{ }^{\circ} \mathrm{C}\right.$ for $\left.33 \mathrm{~min}\right)$ were darker than oil from cashews roasted at low temperature/long time $\left(70{ }^{\circ} \mathrm{C}\right.$ for $6 \mathrm{~h}$ ), and this was attributed the presence of Maillard browning products (Chandrasekara and Shahidi 2011). In response to temperature, total tocopherols decreased progressively from 147 to $177^{\circ} \mathrm{C}$, but increased slightly between 177 and $187^{\circ} \mathrm{C}$ (Figure 4B). In general, though, total tocopherols of samples roasted at higher temperatures $\left(167\right.$ to $\left.187^{\circ} \mathrm{C}\right)$ were lower than those roasted at lower temperatures $\left(147\right.$ and $157^{\circ} \mathrm{C}$ ). This suggests that at increased temperatures, tocopherol degradation surpassed oxidative protection by Maillard browning products. However, given that tocopherol contents of oils from $187^{\circ} \mathrm{C}$ samples were significantly higher than those from $177^{\circ} \mathrm{C}$ samples, it is possible that some protection may be afforded by high temperature/short time conditions. Extended roast temperature data bracketing these temperatures is needed to confirm this possibility.

To further evaluate tocopherol stability, expressed oils were placed in accelerated oxidative conditions for $3 \mathrm{~d}$. Across all oils, total tocopherol content did not significantly $(P<0.05)$ change after $1 \mathrm{~d}$ of accelerated storage; however, after $3 \mathrm{~d}$ of storage, total tocopherol content across all oils was significantly $(P<0.05)$ decreased (Figure 4C). This is in contrast to a previous, related study, in which tocopherol contents in expressed oils from darker roasted seed had increased stability compared to oils extracted from raw or light colored peanuts (all samples roasted at an equivalent temperature) during storage under abusive conditions (Davis and others 2010). In the previous study, however, total tocopherol contents were roughly equivalent prior to exposure to accelerated oxidative conditions (Davis and others 2010), whereas in the current study, tocopherol contents prior to storage varied according to roast color as previously described. This suggests that tocopherol degradation had already begun as oil samples were being prepared for the accelerated oxidative study, which might have lessened the effects expected during storage. Oils were sampled again after $7 \mathrm{~d}$ of accelerated storage but extensive tocopherol degradation hindered quantification.

Tocopherol content correlated well with final MC (Figure 3B) as samples with lower MC generally had higher levels of tocopherols. The presence of water enhances oxidation potential within a food that could be a direct mechanism for this relationship. Additionally, MC was typically lower in samples roasted to darker colors. These samples also had increased concentrations of Maillard browning products, which seemingly protect tocopherols from degradation. 
Lower moisture, increased Maillard browning, and higher tocopherol contents could point toward increased shelf life for darker roasted peanuts.

PV is a measurement of primary oxidation products, and increased PVs are indicative of lipid oxidation. PVs of oil from roasted peanuts stored under accelerated oxidative conditions for $7 \mathrm{~d}$ were related to roast temperature and increased with increasing temperature up to $177^{\circ} \mathrm{C}$, then leveled off at $187^{\circ} \mathrm{C}$ (data not shown). A curvilinear relationship between oil PV after $7 \mathrm{~d}$ storage compared with oil total tocopherol content after $3 \mathrm{~d}$ storage was observed, and oils with higher levels of tocopherols had lower PVs (Figure 5). Data in Figure 5 was reasonably well described $\left(R^{2}=\right.$ $0.75)$ by an exponential decay model of the form:

$$
y=a e^{-b x}
$$

where $\mathrm{y}=$ oil PV at $7 \mathrm{~d}, \mathrm{x}=$ total tocopherol content at $3 \mathrm{~d}$, and "a" and "b" are constants. A similar relationship between PV and tocopherols was observed in stored raw and dry roasted peanuts (Chun and others 2005). PV data, however, must be interpreted with caution because oxidation products undergo formation, stabilization, and decomposition phases. So although a sample may have a lower PV, peroxides quickly degrade during secondary stages of oxidation, and since PV data was only collected after $7 \mathrm{~d}$ due to logistical considerations, the data must be interpreted with this caveat.

\section{Hydrophilic-oxygen radical absorbance capacity}

Antioxidant capacities of raw and roasted samples and corresponding skins were measured using the H-ORAC assay. $\mathrm{H}-$ ORAC of raw, blanched peanuts was $5174 \pm 204 \mu$ mol Trolox equivalents (TE)/100 g DW. Roasting increased H-ORAC of peanut seed to $7121 \pm 792 \mu \mathrm{mol}$ TE/100 g DW across all roasted samples, which represents a $38 \%$ increase due to roasting. No differences were observed in $\mathrm{H}-\mathrm{ORAC}$ for peanuts roasted to different colors or at different roast temperatures, although trends did suggest increasing $\mathrm{H}-\mathrm{ORAC}$ with darkening color. The increase in H-ORAC from raw to roasted samples agrees with previous studies that demonstrated that roasting increases antioxidant capacity (Davis and others 2010; Talcott and others 2005). Roasting increases hydrophilic antioxidant capacity due to Maillard browning (Oliviero and others 2009) and/or the release of previously bound phenolic compounds (Talcott and others 2005).
During commercial roasting, peanut skins are typically removed and sold at low cost for use in animal feed (Sobolev and Cole 2004). H-ORAC of peanut skins averaged $156263 \mu \mathrm{mol} \mathrm{TE} / 100 \mathrm{~g} \mathrm{DW}$, which was approximately 30- and 22-fold higher than raw and roasted peanut seed, respectively. These exceptionally high $\mathrm{H}-$ ORAC values are due to the naturally high polyphenolic content of peanut skins. No obvious trends in peanut skin H-ORAC with roast treatment were observed. Current values agree with previously reported H-ORAC data on peanut skins (Davis and others 2010), and these data support recent research highlighting the excellent potential of peanut skins, a current by-product of the peanut industry, to serve as a natural source of antioxidants and other health-promoting compounds (Francisco and Resurreccion 2012; Yu and others 2005).

\section{Mechanical compression}

Roasting changes the internal microstructure of the peanut and other oilseeds resulting in a texture that is typically more brittle, crispy, and/or crunchy (Lee and Resurreccion 2006). Mechanical properties of the roasted seeds have been used to predict human

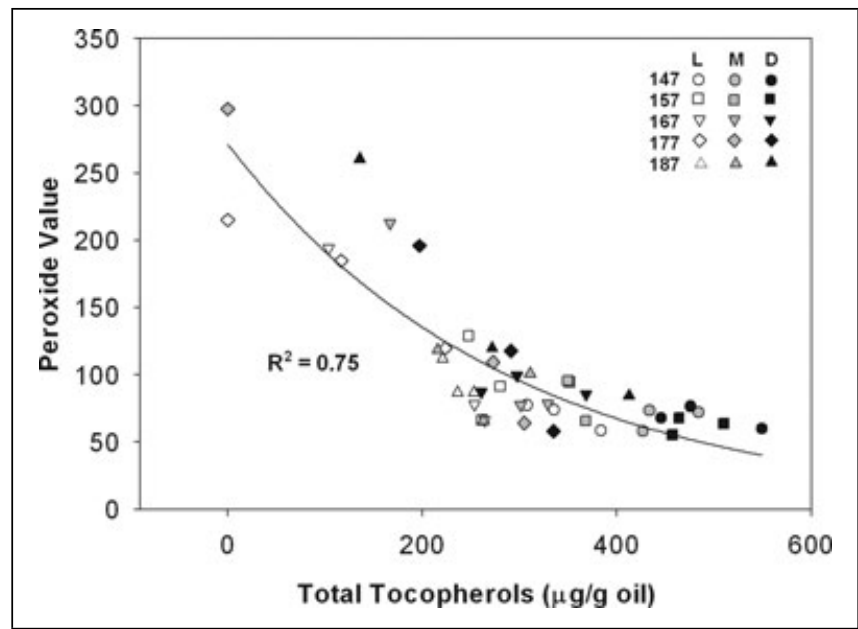

Figure 5-Peroxide value of oils at $7 \mathrm{~d}$ of accelerated storage against total tocopherol contents of oils after $3 \mathrm{~d}$ of accelerated storage. Oils were expressed from peanuts roasted using various time/temperature combinations. See text for details. Line is an "exponential decay" fit of the data.

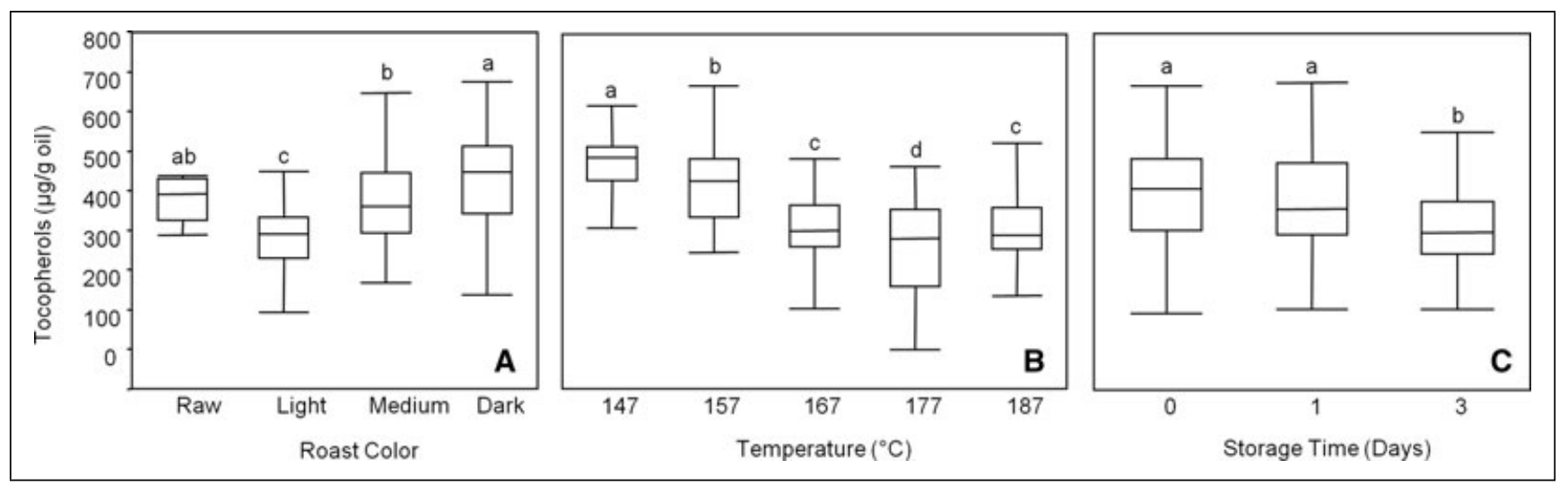

Figure 4-Total tocopherol content of roasted peanuts in response to roast color (A), roast temperature (B), and storage time (C). Box plots separated by different letters are significantly different $(P<0.05)$. In the box plots, the bottom of the box represents the 25 th quantile, the top of the box represents the 75th quantile, and the line within each box represents the sample median. The whiskers on the plots represent the minimum and maximum data points. 
Table 4-Peak force upon compression of raw peanuts and peanuts roasted to different colors averaged across all roast temperatures.

\begin{tabular}{ll}
\hline Roast color & Peak force $(\mathbf{N})$ \\
\hline Raw & $1606.2 \pm 7.9 \mathrm{a}^{\mathrm{a}, \mathrm{b}}$ \\
Light & $1423.3 \pm 68.9 \mathrm{~b}$ \\
Medium & $1375.3 \pm 42.0 \mathrm{c}$ \\
Dark & $1362.1 \pm 63.5 \mathrm{c}$ \\
\hline
\end{tabular}

${ }^{a}$ Values represent means \pm standard deviation $(n=3)$.

${ }^{b}$ Values within each column followed by different letters are significantly different $(P<0.05)$

textural perception. Due to the nonuniform size of peanuts and other oilseeds, previous work has shown that bulk (multiple seed) compression produces results more relevant to human textual perception than single seed compression (Hung and Chinnan 1989). Therefore, a multiple seed compression test was used to create force compared with displacement curves for the current roasted samples, which in turn were used to make inferences on roasted peanut texture based on the peak value from the curves (Wanlapa and Jindal 2006).

Peak force upon compression decreased as a result of roasting and was dependent upon roast color but not roast temperature (Table 4). Medium and dark roast peanuts had a lower max force at fracture than did light roast peanuts, and this finding this is in agreement for similar data for roasted cashews (Wanlapa and Jindal 2006) and roasted hazelnuts (Saklar and others 1999). Decreases in peak force at compression have been associated with increased sensory scores of crunchiness and/or crispiness for various roasted oilseeds (Saklar and others 1999; Varela and others 2008; Wanlapa and Jindal 2006). Moisture loss is thought to be a critical factor in developing texture during roasting (Ozdemir and others 2001). There was good correlation between peak force and moisture of roasted samples (Figure 3C). Light roasts tend to have higher moisture along with higher peak force followed by medium and dark roasts. Decreasing $\mathrm{MC}$, which is related to roasting conditions, correlates with increases crispiness and/or crunchiness of almonds (Varela and others 2008), cashews (Wanlapa and Jindal 2006), and hazelnuts (Saklar and others 1999).

\section{Conclusions}

Roasting significantly affected various compositional and mechanical properties of peanuts. Final roast color appeared to be the most important factor affecting many quality parameters; however, $\mathrm{MC}$, fructose, soluble protein, and tocopherols were all dependent upon roast temperature. This suggests that peanuts roasted to equivalent surface colors at different time/temperature combinations are not equivalent from a quality perspective. Differences in these compositional parameters are expected to have significant effects on flavor, texture, shelf life, and even digestibility of the roasted product. Final MC of the roasted peanuts was strongly related to soluble protein concentration, tocopherol concentration, and peak force measured during compression testing. A high temperature/short time roasting process resulted in peanuts with higher moisture, and this was particularly favorable for soluble protein contents. Maillard browning products appeared to be protective against tocopherol degradation and lipid oxidation as oil from dark roasted peanuts retained more tocopherols, and oils that retained more tocopherols had lower PVs. Information from this study should be considered holistically and in conjunction with flavor data, which will be presented in a subsequent manuscript, to optimize peanut roasting to improve various aspects of final product quality.

\section{References}

Baker GL, Cornell JA, Gorbet DW, O'Keefe SF, Sims CA, Talcott ST. 2003. Determination of pyrazine and flavor variations in peanut genotypes during roasting. J Food Sci 68(1):394-400. Chandrasekara N, Shahidi F. 2011. Oxidative stability of cashew oils from raw and roasted nuts. J Am Oil Chem Soc 88(8):1197-202.

Chetschik I, Granvogl M, Schieberle P. 2010. Quantitation of key peanut aroma compounds in raw peanuts and pan-roasted peanut meal: aroma reconstitution and comparison with commercial peanut products. J Agric Food Chem 58(20):11018-26.

Chun J, Lee J, Eitenmiller RR. 2005. Vitamin E and oxidative stability during storage of raw and dry roasted peanuts packaged under air and vacuum. J Food Sci 70(4):C292-7.

Davis JP, Dean LL, Price KM, Sanders TH. 2010. Roast effects on the hydrophilic and lipophilic antioxidant capacities of peanut flours, blanched peanut seed and peanut skins. Food Chem 119(2):539-47.

Francisco MLd, Resurreccion AVA. 2012. Antioxidant capacity and sensory profiles of peanut skin infusions. LWT Food Sci Technol 47(1):189-98.

Hung YC, Chinnan MS. 1989. Mechanical texture measurement of whole and chopped peanuts. Peanut Sci 16(1):32-7

Kopper RA, Odum NJ, Sen M, Helm RM, Stanley JS, Burks AW. 2005. Peanut protein allergens: the effect of roasting on solubility and allergenicity. Int Arch Allergy Immunol 136(1):16-22.

Lee CM, Resurreccion AVA. 2006. Predicting sensory attribute intensities and consumer acceptance of stored roasted peanuts using instrumental measurements. J Food Qual 29(4):319-38

Maleki SJ, Chung SY, Champagne ET, Raufman JP. 2000. The effects of roasting on the allergenic properties of peanut proteins. J Allergy Clin Immunol 106(4):763-8.

Manzocco L, Calligaris S, Mastrocola D, Nicoli MC, Lerici CR. 2000. Review of nonenzymatic browning and antioxidant capacity in processed foods. Trends Food Sci Technol 11(9-10):340-6.

Oliviero T, Capuano E, Caemmerer B, Fogliano V. 2009. Influence of roasting on the antioxidant activity and HMF formation of a cocoa bean model systems. J Agric Food Chem 57(1):147-52.

Ozdemir M, Seyhan FG, Bakan AK, Ilter S, Ozay G, Devres O. 2001. Analysis of internal browning of roasted hazelnuts. Food Chem 73(2):191-6.

Pattee HE, Giesbrecht FG, Young CT. 1991. Comparison of peanut butter color determination by CIELAB $L^{*} a^{*} b^{*}$ and Hunter color-difference methods and the relationship of roasted peanut color to roasted peanut flavor Response. J Agric Food Chem 39(3):519-23.

Pattee HE, Isleib TG, Giesbrecht FG, McFeeters RF. 2000. Investigations into genotypic variations of peanut carbohydrates. J Agric Food Chem 48(3):750-6.

Prior RL, Hoang H, Gu LW, Wu XL, Bacchiocca M, Howard L, Hampsch-Woodill M, Huang DJ, Ou BX, Jacob R. 2003. Assays for hydrophilic and lipophilic antioxidant capacity (oxygen radical absorbance capacity (ORAC(FL))) of plasma and other biological and food samples. J Agric Food Chem 51(11):3273-9.

Reyes FGR, Poocharoen B, Wrolstad RE. 1982. Maillard browning reaction of sugar-glycine model systems-changes in sugar concentration, color and appearance. J Food Sci 47(4):1376-7.

Saalia FK, Phillips RD. 2011. Degradation of aflatoxins by extrusion cooking: effects on nutritional quality of extrudates. LWT Food Sci Technol 44(6):1496-501.

Saklar S, Ungan S, Katnas S. 1999. Instrumental crispness and crunchiness of roasted hazelnuts and correlations with sensory assessment. J Food Sci 64(6):1015-9.

Sanders TH, Vercellotti JR, Crippen KL, Civille GV. 1989. Effect of maturity on roast color and descriptive flavor of peanuts. J Food Sci 54(2):475-7.

Schirack AV, Drake MA, Sanders TH, Sandeep KP. 2006. Characterization of aroma-active compounds in microwave blanched peanuts. J Food Sci 71(9):C513-20.

Sobolev VS, Cole RJ. 2004. Note on utilisation of peanut seed testa. J Sci Food Agric 84(1):105-11

Talcott ST, Passeretti S, Duncan CE, Gorbet DW. 2005. Polyphenolic content and sensory properties of normal and high oleic acid peanuts. Food Chem 90(3):379-88.

van Boekel M, Fogliano V, Pellegrini N, Stanton C, Scholz G, Lalljie S, Somoza V, Knorr D, Jasti PR, Eisenbrand G. 2010. A review on the beneficial aspects of food processing. Mol Nutr Food Res 54(9):1215-47.

Varela P, Salvador A, Fisman S. 2008. On the assessment of fracture in brittle foods: the case of roasted almonds. Food Res Int 41(5):544-51.

Wanlapa A, Jindal VK. 2006. Instrumental and sensory evaluation of textural changes during roasting of cashew kernels. J Text Stud 37(3):263-75.

Wu XL, Gu LW, Holden J, Haytowitz DB, Gebhardt SE, Beecher G, Prior RL. 2004. Development of a database for total antioxidant capacity in foods: a preliminary study. J Food Compos Anal 17(3-4):407-22.

Yilmaz Y, Toledo R. 2005. Antioxidant activity of water-soluble Maillard reaction products. Food Chem 93(2):273-8.

Yu JM, Ahmedna M, Goktepe P. 2005. Effects of processing methods and extraction solvents on concentration and antioxidant activity of peanut skin phenolics. Food Chem 90(1-2):199-206. 